Fuentes para la historia de Ceuta y Melilla en la Sección de Fondos Contemporáneos del Archivo Histórico Nacional

ISABEL PALOMERA PARRA

JESÚS GAITE PASTOR

INTRODUCCIÓN

La Sección Fondos Contemporáneos del Archivo Histórico Nacional alberga entre otros los documentos producidos por el Ministerio de Hacienda y organismos que le precedieron en sus funciones hasta aproximadamente el año 1939; es lo que don Antonio Matilla Tascón denominó "Fondo Antiguo" y que lue por él descrito en su Guía de los Fondos Históricos del Archivo Central del Ministerio de Hacienda (1).

Esta documentación procedente del Archivo Central del Ministerio de Hacienda resultó muy diezmada durante la Guerra Civil, al servir el Archivo como sede de la Junta de Defensa de Madrid, siendo transferida al Archivo Histórico Vacional en el año 1962.

$\mathrm{Y}$ es dentro de este conjunto documental, constituido por 13.946 legajos y 10.679 libros (2), donde se localiza una de sus series más importantes la de "Propiedades y Desamortización", cuyas fechas extremas comprenden desde el siglo XVIII al siglo XX; se recoge aquí documentación que permite investigar sobre todo "el proceso desamortizador y la administración por parte del Estado de los bienes adquiridos pero no enajenados" (3). 
Este fondo procede de la Dirección General de Propiedades y Contribución Territorial creada por R. D. de 15 de diciembre de 1925 (Ministerio de Hacienda G.26), que tendrá a su cargo entre otras competencias las Propiedades y Derechos del Estado.

Por Decreto de 19 de septiembre de 1934 (Ministerio de Hacienda G.25), se organiza una Dirección General de Contribución Territorial con independencia de la de Propiedades y Derechos del Estado.

Para el tema objeto de esta comunicación dentro de la serie mencionada, se conserva documentaciónn sobre cesiones de terreno, en concreto, al Ramo de Guerra con especial referencia a Ceuta y Melilla en los legajos n" 12.688, $12.689,12.690$ y 12.819 que aparecen descritos en el "Índice Topográfico de legajos" como "Expedientes de Propiedades de Marruecos".

Existe un Inventario (4) en el que se recogen inventariados una tercera parte de estos fondos, con sendos Índices geográfico, de materias y organismos.

Aunque inventariados, con motivo de este trabajo se han descrito más en profundidad estos cuatro legajos, realizándose el catálogo que aquí presentamos (V. anexo I).

Las fechas extremas de la documentación van desde 1899 a 1952, pero la más abundante se sitúa entre los años 1920-1930.

El tema principal de este conjunto documental es la regulación del estado jurídico de la propiedad de los terrenos en Ceuta y Melilla.

Para comprender esta cuestión haremos una breve historia de la situación.

Los territorios de soberanía nacional en que estaban enclavadas las plazas de Ceuta y Melilla dependían del Ministerio de la Guerra; por R. O. de 13 de agosto de 1920 de este organismo, dictada de acuerdo con lo informado por el Consejo de Estado en pleno, se resolvió la entrega al Ministerio de Hacienda de todos los terrenos de dichos territorios propiedad del Estado, salvo los que fueran necesarios para usos militares los cuales continuarían en poder del Ministerio de la Guerra. 

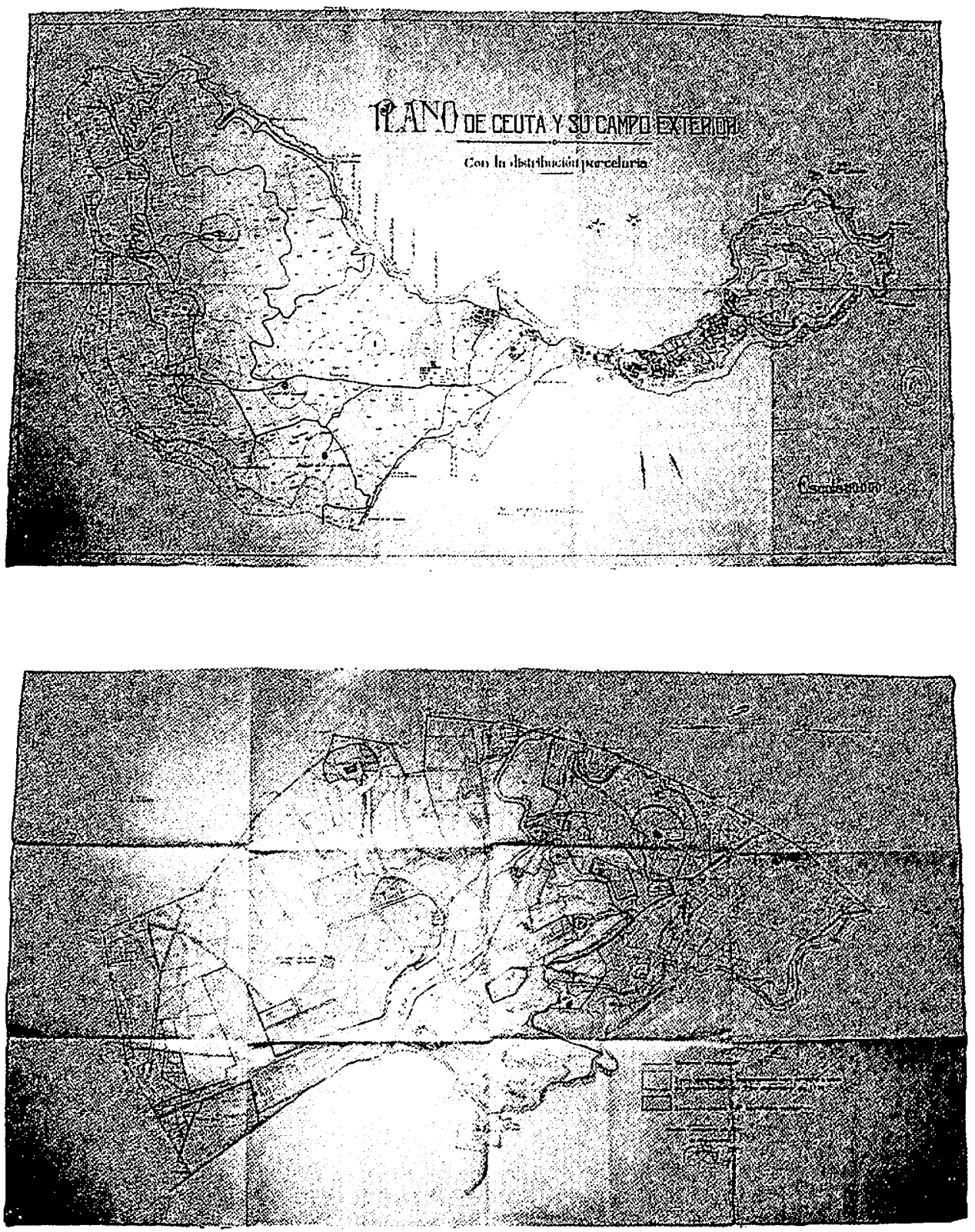
Los territorios propiedad del Estado no podrían ser enajenados por éste, sin oír previamente al Ramo de Guerra, y en los terrenos cedidos a particulares o entidades, para edificación o cultivo, la Hacienda ejercitaría los derechos que el Estado pudiera hacer valer sobre ellos.

Otro jalón importante supuso el R. D. Ley de 27 de marzo de 1925 de Presidencia del Directorio Militar, en el que se señalaba que todos los terrenos eran propiedad exclusiva del Estado; se accedía a legitimar al Ramo de Guerra, de modo definitivo las concesiones que le habían sido hechas de terrenos indispensables para la defensa de las Plazas; cedía gratuitamente a los Municipios de Ceuta y Melilla cuantos terrenos pudieran necesitar para fines de urbanización; y de los restantes terrenos propiedad del Estado habían de legitimarse, dando incluso facilidades para su pago, todos los concedidos a particulares; formándose un inventario de los restantes cuyo arriendo o venta quedaba a cargo de unas Comisiones Administradoras, cediéndose por espacio de 15 años a los municipios de Ceuta y Melilla el $95 \%$ del producto o beneficio obtenido con esos terrenos sobrantes.

El orden establecido no podía ser más lógico: ante todo, las necesidades militares de guerra para la defensa de las plazas, después cuanto fuese necesario para urbanización, seguidamente los intereses de los usufructuarios y en último extremo los de la Corporación Municipal con una participación sólo del $5 \%$ a favor del Estado.

De la aplicación y consecuencias de estas disposiciones se generó la documentación que nos ocupa.

\section{LAS INSTITLGIONES}

Al tratar este punto es fundamental preguntarse ¿Qué instituciones generaron esta documentación? La respuesta es que muchas estuvieron presentes: Dirección General de Marruecos y Colonias, Ministerio de la Guerra, Alta Comisaría de España en Marruecos, Presidencia del Gobierno Provisional de la República Española, etc. Pero las que directamente fue- 
ron creadas para solucionar el problema de distribución de parcelas y legitimación de terrenos en Ceuta y Melilla son fundamentalmente tres:

1. Las Comisiones Mixtas Transitorias Legitimadoras de la Propiedad Territorial en Ceuta y Melilla.

2. Las Comisiones Mixtas Administradoras del Patrimonio del Estado en Ceuta y Melilla.

3. Las Administraciones Especiales del Patrimonio del Estado en Ceuta $y$ Melilla.

LAS COMSIONES MIXTAS TRANSITORLAS LEGITIMADORAS DE LA PROPILDAD TERRITORIAI.

EN CEUTA Y MLLILLA

Creadas por R. D. de 27 de marzo de 1925 de Presidencia del Directorio Militar (G.29). Quedaron constituidas formalmente el 1 de mayo de 1925.

Su finalidad como su nombre indica, era la de legitimar la propiedad, resolviendo las peticiones de los usufructuarios de parcelas, protegiendo al pequeño colono, en definitiva legalizar la situación de los terrenos de Ceuta y Melilla.

La Comisión Transitoria negó el derecho a capitalizar los terrenos que usufructuaban gran número de particulares por no haber completado su expediente en los plazos concedidos para ello. Las concesiones no legitimadas pasarían a formar parte del Patrimonio del Estado y podían ser enajenadas por la Comisión Mixta Administradora que sucedía a la Transitoria.

Sus trabajos debían terminar el 19 de noviembre de 1925, haciendo entrega a la Junta de Arbitrios de los terrenos necesarios para fines de urbanización: sin embargo la vida de estas Comisiones fue prorrogada por R. D. de 26 de noviembre de 1925, al no haber remitido la Superioridad determinados datos necesarios para hacer entrega a la Junta de Arbitrios de las fincas necesarias para fines de urbanización y ser imposible terminar la vasta labor a realizar.

El 27 de julio de 1925 habían hecho entrega ya de los terrenos correspondientes al Ramo de Guerra.

Por R. D. de 9 de abril de 1929 (G.12) se decreta la suspensión de estas Comisiones. 
Se crean por R. D. de 31 de octubre de 1927, sustituyendo en sus trabajos a las anteriores.

Mediante una Orden de 6 de junio de 1931 de la Presidencia del Gobiemo Provisional de la República, se dispone que pasen a depender del Ministerio de Hacienda, y que este Departamento sea el competente en todas las cuestiones relacionadas con las propiedades del Estado en aquellas plazas, dejando de intervenir en las mismas la Dirección General de Marruecos y Colonias.

Una de las funciones encomendadas a estas Comisiones era la de redención de cánones: cuando fueron suspendidas en sus funciones por Orden del Ministerio de Ilacienda de 22 de julio de 1931, se produjo según la documentación (leg. 12.690/4) “... una verdadera perturbación pues además de paralizar el movimiento constructivo en esta ciudad (Melilla), ya que en virtud de aquella medida no pueden concederse nuevos solares lo cual contribuye a aumentar el paro forzoso entre los obreros y a mantener la elevación de los alquileres, han quedado igualmente en suspenso las operaciones de transmisión de dominio entre el Estado y particulares...".

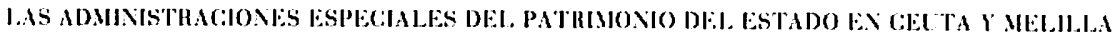

Se crean por Ley de 29 de junio de 1933, recogiendo la documentación entregada por las Comisiones Mixtas del Patrimonio del Estado.

Dependen de la Dirección General de Propiedades y Contribución Territorial.

La documentación que contienen estos cuatro legajos es muy variada:

- Existe documentación relativa a las propias Comisiones Transitorias, Mixtas y Administraciones Especiales, referente a su creación, trabajos realizados, supresión y personal; en algunos casos se incluyen inventarios de los efectos y de la documentación de estos Organismos (leg. 12.688).

- Se encuentra asimismo documentación de carácter militar relativa a los terrenos que se consideraban necesarios para fines militares y que el Ramo de Guerra quería reservarse (leg. 12.689).

- Hay documentación generada tras las abundantes solicitudes llevadas a cabo por particulares para que se les reconozcan sus derechos sobre los 
terrenos que tenían arrendados desde antaño. Se incluye aquí la abundante documentación relativa a las parcelas del Campo Exterior de Ceuta, que se encontraba dividido en 262 parcelas, usufructuadas por particulares, corporaciones y Ramo de Guerra.

Estas parcelas se entregaron bajo la condición de que los usufructuarios cumpliesen las determinadas condiciones siguientes: las parcelas se concedieron a censo enfitéutico, obligándose los concesionarios a no poder gravar con hipotecas ni enajenar el todo o parte de lo concedido sin la aprobación del Gobierno; a roturar la tercera parte dentro de los seis primeros meses, y el resto en el año; a construir una casa en cl sitio que se le designase y del modelo que se aprobase, construcción que debía elevarse antes de finalizar el año; a no talar el arbolado existente, antes bien fomentarlo y plantar nuevo en proporción al espacio adquirido y a satisfacer los gastos de deslinde, amojonamiento y derecho de escritura.

- Y una serie documental que abarca desde los años 1946-1952, que trata de expedientes de cesión de terrenos propiedad del Estado a los Ayuntamientos en concepto de bienes de propios; cuya tramitación es igual en todos ellos:

- La Administración Especial del Patrimonio del Estado en Ceuta o Melilla eleva un oficio a la Dirección General de Propiedades y Contribución Territorial para que se considere el expediente de cesión al Ayuntamiento de unos terrenos denominados "parcela número...".

- Otro oficio de la Administración Especial de Patrimonio de Estado, detalla la superficie de la parcela solicitada.

- En el expediente queda una minuta de cumplimiento de la Dirección General de Propiedades y Contribución Territorial, Sección Propiedades, Negociado Marruecos, como testimonio de la resolución enviada al Administrador Especial del Patrimonio del Estado de Ceuta.

- Oficio de acuse de recibo de la Administración Especial del Patrimonio del Estado dirigido al Director General de Propiedades y Contribución Territorial comunicándole haber recibido la Orden Ministerial de cesión en concepto de bienes de propios (Leg. 12.819 . Expedientes 5-71). 
No quisiera terminar esta comunicación sin señalar la existencia de otras fuentes sobre la Administración Española en África.

1. En los Fondos procedentes de la Presidencia de Gobierno, dentro de la serie "Dictadura de Primo de Rivera" años 1923-1930, se localiza una subserie denominada "Ponencias del Directorio Militar", en la que se recoge documentación tramitada por los vocales del denominado Directorio Militar, establecido por el General don Miguel Primo de Rivera desde el 15 de septiembre de 1923 al 3 de diciembre de 1925. siendo los vocales de este Directorio nueve Generales del Ejército que tenían asignadas las diferentes competencias ministeriales; los asuntos eran informados en Ponencias.

Existe un Inventario (5) de estos fondos que incluye unos Índices, que permiten localizar la documentación sobre Ceuta, Melilla y Protectorado de Marruecos; los temas son interesantes y variados: documentos del Ministerio de la Guerra, personal del Ejército destinados en las Plazas de Soberanía. solicitudes de particulares, comercio, suministros del Ejército, creación del Obispado de Ceuta, Sociedades, obras, instalación del ferrocarril, etc.

Dentro de la serie "Asuntos Generales", existe documentación sobre Marruecos, como el viaje a África de Primo de Rivera (leg. 170, expedientes 8.081-8.280), fin de la Campaña de Marruecos (leg. 176, expedientes 9.181-9.390), Impresos, etc.

2. Fondos del Tribunal Supremo, se incluye aquí el denominado "Fondo Reservado", constituido por 52 procesos judiciales que abarcan desde el año 1916 a 1938. Se tratan asuntos de tal magnitud como los de Rebelión Militar, Falsedad, Cohecho, Malversación de Fondos, sucesos como los de Jaca, Casas Viejas, Revolución de Asturias...

Entre esta documentación, tan interesante desde el punto de vista político, se encuentra el denominado "Expediente Picasso", año 1921; este sumario cuenta con la abultada cantidad de diez piezas judiciales resultado del informe llevado a cabo tras el Desastre de Annual y que fue encargado al General de este nombre. Incluye planos. 
INl:Xo 1

Sección: Fondos Contemporáneos

Fondo: Vinisterio de Hacjenda

Serie: Propiedades y Desamortización

Ciaja "1" 12.088

Exp. 1

Fochus: 1922-1930

Descripción: Documentación varia -oficios, telegramas, polictos...- de las Comisiones . Vixtas Legitimadoras de la Propiedad Territorial en Ceuta y Melilla solbre legitimaciones de parcelas. Incluye:

-Copia del Registro de las parcelas de terrenos existentes en el Campo Exterior de Ceuna con expresión de sus usulfucturarios, cabida. límites y situación. 1922-23. Realizarlo por la Comandancia Gemeral de Ceuta.

- Informe sobre las parelas del Campo Exterior de Centa. 1923. Realizado por la Comandancia de lngenieros do Cinta.

- Expediente sobre entrega de terrenos de las Plazas de Cienta y Melilla por el Vinisterio de la Guerra al de I lacienda según R. O. de 133 de agosto de 1920.

\section{Caja n" 12.088}

Exp. 2

Fechas: 1928-1929

Descripción: Expediente solure supresión de las Comisiones Mixtas Transitorias para la legitimación de la propicdad territorial de Centa y Melilla según R. D. de 9 de abril de 1929 y entrega de documentos, mobiliario y efectos a las Comisiones Mixtas Administradoras del Patrimonio del Estado en Centa y Melilla. Incluye: Acta de Entrega, Inventarios y Memoria.

Caja ॥" 12.688

Exp. :3

Fenhas: 1928-1931 
Descripción: Documentación relativa a las Comisiones Mixtas Administradoras del Patrimonio del Estado en Ceuta y Melilla sobre nombramientos de personal, sueldos. Reglamento, presupuestos, etc.

Gaja n" 12.688

Exp. 4

Fechas: 1922-1930

Descripción: Varios expedientes sobre tcrenos en Ceuta y Melilla:

- Aprobación de relación de fincas afectadas por plusvalía.

- Solicitudes de arriendo por antiguos colonos de la margen izquierda de Río de Oro (Melilla).

- Sobre edificación de viviendas clandestinas.

- Capitalización de solares sitos en el Barrio de la Alcazaba de Melilla.

- Planos.

Caja n" 12.089

Exp. 1

Fechas: 1924-1931

Descripción: Expedientes rle Particulares solicitando de la Dirección General de Marruecos y Colonias que se segreguen parcelas destinadas a guera que usufructúan los solicitantes en el Campo lixterior de Cieuta. Incluyen copias de Escrituras y planos.

Ciaja n" 12.689

Exp. 2

Fechas: 1909-1927

Descripción: Expedientes relativos a parcelas concedidas a particulares y calificadas por la Comisión Mixta Transitoria de Ceuta como de redención dudosa por diversas causas. Incluye cuestionarios de preguntas que deben ser contestadas por los concesionarios y remitidos a la Comisión para facilitar la estadística. Icluyen planos.

Caja n" 12.689

Exp. 3

Fechas: 1925-1931 
Descripción: Expediente formarlo para precisar los terrenos que son necesarios en Ceuta y Melilla para fines militares siendo los restantes entregados a la Comisión Mixta Administradora de Patrimonio del Estado procediendo ésta a redimir las concesiones a particulares y el resto serán explotadas por la Comisión. Incluye informe relativo a los terrenos necesarios al Ramo de Guerra para fines militares elaborado por la Comandancia de Ingenieros de Cieuta. Hay planos.

Caja I" 12.689

Exp. 4

Fechas: 1925-1929

Descripción: Expediente solure proyectos de urbanización de la $1^{4}$ y $2^{n}$ zona del Ensanche de Ceuta y de los barrios extremos de Velilla. Hay planos.

Caja ॥" 12.689

Exp. 5

Fechas: 1924-1928

Descripción: Expediente sobre claboración de informe y petición de antecedentes relativos a la legitimación de parcelas en terrenos de Ceuta y Melilla. Hay planos.

Caja n" 12.690

Exp. 1

Fecha: 1933

Descripción: Fichero ordenado alfabéticamente, onomástico, geográfico, de instituciones y materias relativo a los terrenos de Ceuta y Melilla.

Ciaja n" 12.690

Exp. 2

Fechas: 1919-1922

Descripeción: Expediente instruido en virtud de peticiones de la Cámara Oficial Agricola de Cieuta y la Asociación de Agricultores de Melilla solicitando el establecimiento de un estado jurídico definitivo sobre la propiedad de los terrenos del Campo Exterior de Ceuta y. Welilla que fueron cedidos por el Ministerio de la Guerra a los agricultores. Resolución favorable publicada como Ley el 4 de agosto de 1922. Incluye: dos ejempla- 
res impresos del diario El Telegrama del Rif n" 7263, sábado 22 de enero de 1921 y colección de artículos que se han venido publicando en este diario sobre tierras y terrenos de labor y copia de R. O. de la Presidencia del Consejo de Ministros de 27-X-1920 sobre terrenos del Estado en las posesiones españolas en África.

Caja n"12.690

Exp. 3

Fechas: 1899-1941

Descripción: Expediente instruido a instancia del Gobierno Ecclesiástico de la Diócesis de Ceuta solicitando la nulidad de las subastas de varias casas situadas en Ceuta. Y otros expedientes de particulares solicitando la legitimación de terrenos en Ceuta.

Caja n 12.690

Exp. 4

Fechas: 1927-1936

Descripción: Documentación relativa a la legitimación de terrenos en Melilla. Incluyen documentación sobre sueldos y dietas del personal de la Comisión Mixta Administradora del Patrimonio del Estado. Hay planos.

Caja n" 12.690

Exp. 5

Fechas: 1931-1938

Descripción: Documentación varia relativa a la legitimación de terrenos del Estado en Ceuta y Melilla. Incluye:

- Ley y Reglamento referentes a concesiones, redenciones y legitimaciones de terrenos del Patrimonio del Estado en las zonas de soberanía de Ceuta y Melilla:

- Ejemplar impreso del Extracto Oficial del Congreso de Diputados de jueves 28 de junio de 1934. N 108.

- Expedientes de particulares.

- Certificaciones y oficios remitidos a la Dirección General de Propiedades y Contribución Territorial por las Comisiones Mixtas.

- Ejemplar impreso del Boletín Oficial de Melilla n 148 de 20 de junio de 1931.

- Hay planos. 
Caja n" 12.819

Exp. 1

Fechas: 1939-1940

Descripción: Expediente e instancia de don José Llackó Lara. mutilado de guerra. solicitando la legitimación de un terreno en Ceuta perteneciente a la parcela denominada "Huerta de la Guarnición", cuỵo usufructo le concedió la autoridad militar en mayo 19:39. Hay planos.

Caja "1" 12.819

Exp. 2

Fechas: 1946-1947

Descripción: Expediente sobre consulta del Administrador Especial del Patrimonio del Estarlo sobre si debe otorgarse a los herederos de don Aquiba Benarroch Benclijmol la escritura de capitalización del solar sobre el que está constifuida la casa n" 11 de la e/ Explorador Badía de Melilla o a los de El Hach Molamed Chahabun propietario de la casa.

Caja n" 12.819

Exp. 3

Fechas: 1931-1940

Descripción: Expediente sobre legitimación de la parcela n" 5.3 del Campo lixterior de Ceuta a favor de los hermanos Maese Barrera representados por don José Rubio Conesa oponiéndose a ello el Ayumtamiento. Incluye copia simple de la Escritura de Acta de Requerimiento. Hay planos.

Caja n" 12.819

Exp. 4

Fecha: 1946

Descripción: Expediente sobre la consulta realizada por la Administración Especial del Patrimonio del Estado de Ceuta a la Dirección Gencral de Propiedades y Contribución Territorial sobre si puede concederse la legitimación de parcelas de terreno a los herederos de los concesionarios del usufructo. 
Caja n"12.819

Exp. 5

Fechas: 1946-1947

Descripción: Expediente de cesión de los terrenos y pabellón denominados de "La Alhambra" al Ayuntamiento de Cieuta en concepto de bienes de propios conforme a la Ley de 29 de julio de 1933. Hay plano.

Caja n"12.819

Exp. 6

Fechas: 1946-194?

Descripción: Expediente de cesión de la parcela n" 235 del Campo Exterior de Ceuta sita en la Barriada del Príncipe al Ayuntamiento de Ceuta en concepto de bienes de propios conforme a la Ley de 29 de julio de 1933. Hay plano.

Caja n" 12.819

Exp. 7

Fechas: 1946-1947

Descripción: Expediente de cesión de la parcela n"259 del Campo Exterior de Ceuta sita en la Barriada del Príncipe al Ayuntamiento de Ceuta en concepto de bienes de propios conforme a la Ley de 29 de julio de 1933. Hay plano.

Caja n"12.819

Exp. 8

Fechas: 1946-194?

Descripción: Expediente de propuesta de acuerdo para invitar al Tribunal Económico Administrativo Central a revisar su fallo de 15 de febrero de 1946 y como consecuencia el del Tribunal Provincial de Cádiz de 31 de octubre de 1945 en reclamación interpuesta por don José Rubio Conesa en representación de la familia Maese Barrera sobre legitimación de la parcela 177 del Campo Exterior de Ceuta a favor de dicha familia.

Caja n" 12.819

Exp. 9

Fechas: $1946-1947$ 
Descripción: Expediente sobre negativa del Sr. Registrador de la Propiedad de Ceuta a inscribir la legitimación de la parcela n" 163 del Campo Exterior de Ceuta a favor de don Emilio Martín Giménez por los defectos expresados en la nota que ha estampado al final de la escritura notarial.

Caja n" 12.819

Exp. 10

Fecha: 1947

Descripción: Expediente de cesión del terreno denominado "Huerta de la Farmacia Vilitar" al Ayuntamiento de Ceuta en concepto de bienes de propios conforme a la Ley de 29 de julio de 1933. Hay plano.

Caja n" 12.819

Exp. 11

Fecha: 1947

Descripción: Expediente sobre extravio de documentación en el correo desde la Administración Especial del Patrimonio del Estado de Melilla a la Dirección General de Propiedades y Contribución Territorial.

Caja n' 12.819

Exp. 12

Fecha: 1947

Descripción: Expediente de desestimación de solicitudes de legitimación por no reunir las edificaciones las debidas condiciones de salubridad e higiene en relación con el plan urbanístico de Ceuta.

Caja n" 12.819

Exp. 13

Fecha: 1947

Descripción: Expediente de consulta de la Administración Especial del Patrimonio del Estado en Ceuta respecto a la forma en que deben practicarse las liquidaciones por legitimación de terrenos a pagar en cinco anualidades. 
Caja n" 12.819

Exp. 14

Fecha: 1947

Descripción: Expediente de cesión al Ayumtamiento de Cieuta del terreno ocupado por el lustituto Hispano-Marroquí de Enseñanza Media, en concepto de bienes de propios.

Caja n" 12.819

Exp. 15

Pecha: 1947

Descripción: Expediente sobre petición de legitimación de terrenos por la Companía Española de Fomento en África (CEFA) de la parcela $6 ?$ y parte de la 250 del Campo Exterior de Centa con oposición de la Jelatura de Obras Públicas de Cieuta.

Caja n" 12.819

Exp. 16

Fecha: 1948

Descripción: Expediente de denuncia formulada ante la Dirección General de Propiedarles y Contribución Territorial por el vecino de Melilla don Francisco González Torres sobre las dificultades puestas por la Administmación Especial del Patrimonio del Estado para verificar la legitimación de unos terrenos que lleva cultivando desde 1901. Hay plano.

Caja n" 12.819

Exp. 17 y 18

Fecha: 1948

Descripción: Expediente de cesión al Ayuntamiento de Ceuta de 7.400 m² $^{2}$ de terreno de la parcela n 170 del Campo Exterior de Ceuta para la edificación de un nuevo Matudero Público. Hay plano.

Caja n" 12.819

Exp. 19

Fecha: 1948

Descripción: Expediente de reclamación por el Ministerio del Ejército contra la legitimación de $17.620,72 \mathrm{~m}^{2}$ de la parcela n" 226 a favor de doña Asunción Muro e 
hijos y pretendida legitimación de 12.428.28 $\mathrm{m}^{2}$ de la misma parcela ocupados por el Servicio de Automovilismo por los mismos señores.

Caja $n^{\circ} 12.819$

Exp. 20

Fechas: 1947-1948

Descripeión: Expediente de entrega de la Ganja Agricola Experimental, sita en el Campo Exterior de Melilla, por el Servicio de Propiedades de la Alta Comisaría de España en Marruecos a la Subdelegación de Hacienda y pretendida cesión de la misma al Aỵutamiento de aquella ciudad. Hay plano.

Caja n"12.819

Exp. 21

Fecha: 194?

Descripción: Expediente incoado a instancia del Alcalde de Ceuta solicitando la cesión del terreno del Cementerio Católico de Santa Catalina situado en el Monte Hacho en el lugar denominado "Punta Almina" al Ayuntamiento en concepto de bienes de propios conforme a la Ley 29 de julio de 19:33. Hay plano.

Caja $1 " 12.819$

Exp. 22

Fechas: $1947-19+9$

Descripción: Expedionte incoado a instancia del Alcalde de Ceuta solicitando la cesión del terreno que ocupa el Cementerio Israelita en concepto de bienes de propios conforme a la Ley 29 de julio de 1933. Hay plano.

Cajı 12.819

Exp. 23

Fechas: 1948-1949

Descripción: Expediente de cesión al Ayuntamiento de Ceuta de una parte del edificio y solar del Instituto Hispano-Marroquí de Enseñanza Media para alineación de una calle y entrega en usufructo al Ramo del Ejército de otra parte de la misma finca para ampliación de servicios del Centro Cultural de los Ejércitos. Hay plano. 
Caja $n^{\circ} 12.819$

Exp. 24

Fecha: 1949

Descripción: Expediente de cesión del terreno ocupado por el Hospitalillo de Infecciosos o Local de Aislamiento de Enfermos Contagiosos al Ayuntamiento de Ceuta en concepto de bienes de propios conforme a la Ley 29 de julio de 1933. Hay plano.

Caja n 12.819

Exp. 25

Fecha: 1949

Descripción: Expediente de cesión del terreno ocupado por el “Grupo Escolar de San Amaro" al Ayuntamiento de Ceuta en concepto de bienes de propios conforme a la Ley 29 de julio de 1933. Hay plano.

Caja n" 12.819

Exp. 26

Fecha: 1949

Descripción: Expediente de cesión del terreno ocupado por Los Jardines y Parque de Recreo de San Amaro al Ayuntamiento de Ceuta en concepto de bienes de propios conforme a la Ley 29 de julio de 1933 . Hay plano.

Caja n“ 12.819

Exp. 27

Fecha: 1949

Descripción: Expediente sobre adjudicación de un solar sito en el Barrio Industrial de Melilla a la Compañía Hispano-Marroquí de Gas y Electricidad S.A. para ampliación de la Central Eléctrica y pretendida cesión de un trozo de otro terreno sito en la calle Alférez Francisco Soriano para instalar una subestación de alumbrado.

Caja n*12.819

Exp. 28

Fecha: 1949 
Descripción: Expediente de cesión del terreno correspondiente a la parcela $n^{\prime \prime} 232$ del Campo Exterior de Ceuta al Ayuntamiento de Ceuta en concepto de bienes de propios conforme a la Ley 29 de julio de 1933. Hay plano.

Caja n" 12.819

Exp. 29

Fecha: 1949

Descripción: Expediente de cesión del terreno correspondiente a la parcela $n^{\circ} 7$ del Campo Exterior de Ceuta al Ayuntamiento de Ceuta en concepto de bienes de propios conforme a la Ley 29 de julio de 1933. Hay plano.

Caja n" 12.819

Exp. 30

Fecha: 1949

Descripción: Expediente de cesión del terreno de los que es propiedad el Patrimonio del Estado en la Parcela señalada con la letra " $J$ " del Campo Exterior de Ceuta en concepto de bienes de propios conforme a la Ley 29 de julio de 1933. Hay plano.

Caja n" 12.819

Exp. 31

Fecha: 1949

Descripción: Expediente de cesión del terreno correspondiente a la parcela $n^{\circ} 185$ del Campo Exterior de Ceuta al Ayuntamiento de Ceuta en concepto de bienes de propios conforme a la Ley 29 de julio de 1933. Hay plano.

Caja n" 12.819

Exp. 32

Fecha: 1949

Descripción: Expediente de cesión del terreno correspondiente a la parcela n" 207 del Campo Exterior de Ceuta al Ayuntamiento de Ceuta en concepto de bienes de propios conforme a la Ley 29 de julio de 1933. Hay plano. 
Ciaja n" 12.819

Exp. 33

Fecha: 1950

Descripción: Expediente de cesión del terreno correspondiente a la parcela $1 " 12$ ? del Campo exterior de Ceuta al Ayuntamiento de: Ceuta en concepto de bienes de propios conforme a la Ley 29 de julio de 1933. Hay plano.

Gaja n" 12.819

E.xp. 34

Fecha: 1950

Descripción: Expediente de cesión del terreno correspondiente a la parcela n" 194 del Campo Exterior de Centa al Ayuntamiento de Ceura en concepto de bienes de propios conforme a la Ley 29 de julio de 1933. Hay plano.

Caja " 12.819

Exp. 35

Fecha: 1950

Descripción: Expediente de cesión del terreno correspondiente a la parcela n"199 del Campo Exterior de Centa al Ayuntamiento de Cienta en concepto de bienes de propios conforme a la Ley 29 de julio de 1933. Hay plano.

Caja n" 12.819

Exp. 36

Fecha: 1950

Descripción: Expediente de cesión del terreno correspondiente a la parcela n"2:36 del Campo Exterior de Ceuta al Ayuntamiento de Ceuta en concepto de bienes de propios conforme a la Ley 29 de julio de 1933. Hay plano.

Ciaja n"12.819

Exp. 37

Feclia: $19 \overline{0} 0$ 
Descripción: Expediente de cesión de la parte de las parcelas n" 1 y 14 no ocupada por el Ramo del Ejército al Ayumtamiento de Ceuta en concepto de bienes de propios conforme a la Ley 29 de julio de 1933. Hay plano.

Caja n" 12.819

Exp. 38

Fecha: 1950

Descripción: Expediente do cesión del terreno correspondiente a la parcela $11 "+7$ del Campo Exterior de Ceuta al Ayuntamiento de Centa en concepto de bienes de propios conforme a la Ley 29 de julio de 1933. Hay plano.

Caja n" 12.819

Exp. 39

Fecha: 1950

Descripción: Expediente de cesión del terreno correspondiente a la parcela $1 " 84$ del Campo Exterior de Ceuta al Ayumamiento de Centa en concepto de bienes de propios conforme a la Ley 29 de julio de 1933. Hay plano.

Caja n" 12.819

Exp. +0

Fecha: 1950

Descripción: Expediente de cesión del terreno correspondiente a la parcela n" $n_{4}$ del Campo Exterior de Ceura al Ayuntamiento de Ceuta en concepto de bienes de propios conforme a la Ley 29 de julio de 1933. Hay plano.

Caja и" 12.819

Exp. 41

Fecha: 1950

Descripción: Expediente de cesión del terreno correspondiente a la parcela n" 110 del Campo Exterior de Ceuta al Ayuntamiento de Ceuta en concepto de bienes de propios conforme a la Ley 29 de julio de 1933. Hay plano. 
Caja n" 12.819

Exp. 42

Fecha: 1950

Descripción: Expediente de cesión del terreno correspondiente a la parcela n" 130 del Campo Exterior de Ceuta al Ayuntamiento de Ceuta en concepto de bienes de propios conforme a la Ley 29 de julio de 19:33. Hay plano.

Caja n" 12.819

Exp. 43

Fecha: 1950

Descripción: Expediente de cesión del terreno correspondiente a la parcela n" 182 del Campo Exterior de Ceuta al Ayuntamiento de Ceuta en concepto de bienes de propios conforme a la Ley 29 de julio de 1933. Hay plano.

Caja n" 12.819

Exp. 44

Fecha: 1950

Descripción: Expediente de cesión del terreno correspondiente a la parcela n" 56 del Campo Exterior de Ceuta al Ayuntamiento de Ceuta en concepto de bienes de propios conforme a la Ley 29 de julio de 1933. Hay plano.

\section{Caja n" 12.819}

Exp. 45

Fecha: 1950

Descripción: Expediente de cesión del terreno correspondiente a la parcela $n^{\prime \prime} 215$ del Campo Exterior de Ceuta al Ayuntamiento de Ceuta en concepto de bienes de propios conforme a la Ley 29 de julio de 1933. Hay plano.

Caja n" 12.819

Exp. 46

Fecha: 1950 
Descripción: Expediente de cesión del terreno correspondiente a la parcela $\mathrm{n}^{\circ} 54$ del Campo Exterior de Ceuta al Ayuntamiento de Ceuta en concepto de bienes de propios conforme a la Ley 29 de julio de 1933. Hay plano.

Caja n" 12.819

Exp. 47

Fecha: 1950

Descripción: Expediente de cesión del terreno correspondiente a la parcela n" 178 del Campo Exterior de Ceuta al Ayuntamiento de Ceuta en concepto de bienes de propios conforme a la Ley 29 de julio de 1933. Hay plano.

Caja n" 12.819

Exp. 48

Fecha: 1950

Descripción: Expediente de cesión del terreno correspondiente a la parcela $n^{\prime \prime} 35$ del Campo Exterior de Ceuta al Ayuntamiento de Ceuta en concepto de bienes de propios conforme a la Ley 29 de julio de 1933. Hay plano.

Caja n" 12.819

Exp. 49

Fecha: 1950

Descripción: Expediente de cesión del terreno correspondiente a la parcela $n^{\prime \prime} 70$ del Campo Exterior de Ceuta al Ayuntamiento de Ceuta en concepto de bienes de propios conforme a la Ley 29 de julio de 1933. Hay plano.

Caja n" 12.819

Exp. 50

Fecha: 1950

Descripción: Expediente de cesión del terreno correspondiente a la parcela n" 111 del Campo Exterior de Ceuta al Ayuntamiento de Ceuta en concepto de bienes de propios conforme a la Ley 29 de julio de 1933. Hay plano. 
Caja n"12.819

Exp. 51

Fechas: $1950-1951$

Descripción: Expediente de cesión del terreno correspondiente a la parcela $n^{\prime \prime} 60$. 77, 217 del Campo Extrrior de Ceuta al Ayuntamiento de Ceuta en concepto de bienes de propios conforme a la Ley 29 de julio de 1933. I lay plano.

Caja n" 12.819

Exp. 52

Fechas: 1950-1951

Descripción: Expediente de cesión del terreno correspondiente a la parcela n" 239 del Campo Exterior do (ieuta al Ayuntamiento de Ceuta en concepto de bienes de propios conforme a la Ley 29 de julio de 1933. Hay plano.

Caja n"12.819

Exp. 53

Fechas: 1950-1951

Descripción: Expediente de cesión del terreno correspondiente a la parcela n" 204 del Campo Exterior de Ceuta al Ayuntamiento de Cieuta en concepto de bienes de propios conforme a la Ley 29 de julio de 1933. Hay plano.

Caja n"12.819

Exp. 54

Fecha: 1951

Descripción: Expediente de cesión del terreno correspondiente a la parcela n" 51 del Campo Exterior de Ceuta al Ayuntamiento de Ceuta en concepto de bienes de propios conforme a la Ley 29 de julio de 1933. Hay plano.

Caja n" 12.819

Exp. 55

Fecha: 1951 
Descripción: Expediente de cesión del terreno correspondiente a la parcela $1 " 62$ del Campo Exterior de Ceuta al Ayuntamiento de Centu en concepto de bienes de propios conforme a la Ley 29 de julio de 1933. Hay plano.

Caja n" 12.819

Exp. इ0

Fecha: 1951

Descripción: Expediente de cesión del terreno correspondiente a la parcela 11 "9.5 del Campo Exterior de Centa al Ayumaniento de Ceuta con concepto de bienes de propios conforme a la Ley 29 de julio de 1933. Hay plano.

Caja n"12.819

Exp. 57

Fecha: 1951

Descripción: Expediente de cesión del terreno correspondiente a la parcela ${ }^{\prime \prime} 112$ del Campo Exterior de Ceuta al Ayuntamiento de Ceuta en concepto de bienes de propios conforme a la ley 29 de julio de 1933. Hay plano.

Caja " 12.819

Exp. 58

Fecha: 1951

Descripción: Expediente de cesión del terreno correspondiente a la parcela " 133 del Campo Exterior de Ceuta al Ayuntamiento de Centa en concepto de bienes de propios conforme a la Ley 29 de julio de 1933. Hay plano.

(iaja n" 12.819

Exp. 59

Fecha: 1951

Descripción: Expediente de cesión del terreno correspondiente a la parcela n"140 del Campo Exterior de Cieuta al Ayuntamiento de Ceuta en concepto de bienes de propios conforme a la Ley 29 de julio de 1933. Hay plano. 
Caja n" 12.819

Exp. 60

Fecha: 1951

Descripción: Expediente de cesión del terreno correspondiente a la parcela n" 197 del Campo Exterior de Ceuta al Ayuntamiento de Ceuta en concepto de bienes de propios conforme a la Ley 29 de julio de 1933. Hay plano.

Caja n"12.819

Exp. 61

Fecha: 1951

Descripción: Expediente de cesión del terreno correspondiente a la parcela n" 213 del Campo Exterior de Ceuta al Ayuntamiento de Ceuta en concepto de bienes de propios conforme a la Ley 29 de julio de 1933. Hay plano.

Caja n" 12.819

Exp. 62

Fecha: 1951

Descripción: Expediente de cesión del terreno correspondiente a la parcela $n " 43$ del Campo Exterior de Ceuta al Ayuntamiento de Cienta en concepto de bienes de propios conforme a la Ley 29 de julio de 1933. Hay plano.

Caja " 12.819

Exp. 63

Fechas: 1950-1952

Descripción: Expediente de cesión del terreno correspondiente a la parcela n" 143 del Campo Exterior de Ceuta al Ayuntamiento de Ceuta en concepto de bienes de propios conforme a la Ley 29 de julio de 1933. Hay plano.

Caja n" 12.819

Exp. 64

Fechas: 1950-1952 
Descripción: Expediente de cesión del terreno correspondiente a la parcela n" 244 del Campo Exterior de Ceuta al Ayuntamiento de Cieuta en concepto de bienes de propios conforme a la Ley 29 de julio de 1933. Hay plano.

Caja n"12.819

Exp. 65

Fecha: 1952

Descripción: Expediente de cesión del terreno correspondiente a la parcela n" 36 del Campo Exterior de Ceuta al Ayuntamiento de Ceuta en concepto de bienes de propios conforme a la Ley 29 de julio de 1933. Hay plano.

Caja n" 12.819

Exp. 66

Fecha: 1952

Descripción: Expediente de cesión del terreno correspondiente a la parcela $\mathbf{n}^{\mathbf{0}} 101$ del Campo Exterior de Ceuta al Ayuntamiento de Ceuta en concepto de bienes de propios conforme a la Ley 29 de julio de 1933. Hay plano.

Caja n" 12.819

Exp. 6 ?

Fecha: 1952

Descripción: Expediente de cesión del terreno correspondiente a la parcela $n^{0} 126$ del Campo Exterior de Ceuta al Ayuntamiento de Ceuta en concepto de bienes de propios conforme a la Ley 29 de julio de 1933. Hay plano.

Caja n" 12.819

Exp. 68

Fechas: $1948-1952$

Descripción: Expediente sobre antecedentes de la pretendida legitimación del terreno ocupado por el Teatro Ciervantes por don Antonio Delgado Sánchez y otros y reclamación de estos señores contra el acuerdo de sacar a subasta pública dicho terreno. 
Caja n" 12.819

Exp. 69

Fecha: 1952

Descripción: Expediente de cesión del terreno correspondiente a la parcela $n^{\circ} 174$ del Campo Exterior de Ceuta al Ayuntamiento de Ceuta en concepto de bienes de propios conforme a la Ley 29 de julio de 1933. Hay plano.

\section{Caja n" 12.819}

Exp. 70

Fecha: 1952

Descripción: Expediente de cesión del terreno correspondiente a la parcela n" 234 del Campo Exterior de Ceuta al Ayuntamiento de Ceuta en concepto de bienes de propios conforme a la Ley 29 de julio de 1933. Hay plano.

Caja n'12.819

Exp. 71

Fechas: 192:3-1936

Descripción: Expediente sobre reforma del Reglamento de 4 de mayo de 1934 dictado para aplicación de la Ley de 29 de julio de 1933 sobre legitimación de terrenos en Ceuta y Melilla incoado en virtud de ruego hecho al Excmo. Sr. Ministro de Hacienda en las Cortes por el Diputado Tomás Peire. Incluye tres ejemplares impresos de la Gaceta de Madrid de 1 de agosto de 1933: o de mayo de 1934 y 9 de febrero de 1936. 
1. MATIL LA TASCON. Artonio y Marí MARTÍNEZ Y APARICIO, Gúa de los Fondos Históricos del Archiro Centrol del Ministerio de Hacienda. Madrid. Instituto de Esstudios Fiscales, 1962..vol.1.

2. Cuía de la Seccion de Fondos

Contemporáneos redactada por Jesús Gaite Pastor. Madrid, 1988. (Meconografindo, en sala de investigadores del Archivo Histórico Tacional).

3. Guía ste la Sección...: up) cil .. p. 27
4. Inrentario de los Fondos Procerlentes de In Dirección Gesneral de Propiedades del Estado (... 15.50-19.52...) realizado por Roberto González Miguel bajo la dirección de Jesís Cátite Pastor, Madrid, 1989, 2 vols. (Mecanograliado. Jin sala de investigadores del Archiso Ilistórico Nacional).

5. INVENTARIO de las Ponencias del Dircetorio .Vilitar (192:3-1925). dirigido por Jesís Caite Pastor. Matdrirl. Ministerio de: Cultura. 1988. 